\title{
EFFECTIVENESS OF UNIPEDICULAR KYPHOPLASTY IN OSTEOPOROTIC THORACOLUMBAR VERTEBRAL COMPRESSION FRACTURES IN ELDERLY PATIENTS: A RETROSPECTIVE STUDY
}

\author{
(1) Evren KARAALI, @ FIrat SEYFETTINOĞLU
}

Adana City Training and Research Hospital, Clinic of Orthopaedics and Traumatology, Adana, Turkey

\begin{abstract}
Objective: Discussions regarding the effectiveness of unipedicular kyphoplasty in osteoporotic thoracolumbar vertebral fractures are found in the literature. To evaluate the clinical and radiologic efficacy of percutaneous unipedicular kyphoplasty in thoracolumbar osteoporotic vertebral compression fractures (OVCFs) in elderly patients.

Materials and Methods: Our study was conducted as a retrospective analysis. We enrolled patients who underwent percutaneous unipedicular kyphoplasty due to thoracolumbar OVCFs between January 2015 and December 2018. All patients were evaluated through two-planed radiographs and computed tomography scans. The local kyphosis angle (LKA) and vertebral corpus height (VCH) of the fractured vertebrae were measured. The Visual Analogue scale (VAS) and Oswestry Disability index (ODI) were used to determine the functional outcomes of patients. Results: We included 77 patients (28 men, 49 women) with a mean of age $76.64 \pm 5.5$ years (range, 69-86 years). In this study, all patients showed better improvement in ODI scores and LKA, increased VCH and decreased VAS scores 24 months postoperatively compared with preoperative values ( $p<0.05$ for all). As a local complication, cement leakage from the kyphoplasty cannula tract to the posterior of the corpus was found in six patients, and cement leakage to the anterior was found in four patients.

Conclusion: Percutaneous unipedicular kyphoplasty is a reliable method with satisfactory clinical and radiologic results in thoracolumbar OVCFs in elderly patients.

Keywords: Kyphoplasty, thoracolumbar, compression fracture, osteoporosis
\end{abstract}

\section{INTRODUCTION}

Osteoporosis is a common, chronic, progressive disease characterised by low bone quality and increased risk of fracture with a multifactorial aetiology ${ }^{(1,2)}$. Vertebral compression fractures are the most common fractures associated with osteoporosis ${ }^{(3)}$. These types of fractures are most commonly seen in the lower thoracic and upper lumbar junction ${ }^{(1,4)}$. Osteoporotic vertebral compression fractures (OVCFs) are often caused by low-energy trauma in elderly patients ${ }^{(3)}$. These fractures are associated with increased morbidity and mortality, such as progressive kyphotic deformity and persistent low back pain and severely restricting the daily life activities of patients ${ }^{(3,5)}$. The primary treatment of OVCF is conservative treatment, with bed rest, analgesic and cast-brace ${ }^{(1,4,6)}$. However, the treatment choice is surgery for persistent pain for 4 weeks and progressive kyphotic deformity ${ }^{(1,4,6,7)}$. Surgical treatment provides advantages, such as early mobilisation, recovery of vertebral corpus height $(\mathrm{VCH})$ and correction of kyphotic deformity in addition to reducing pain ${ }^{(6,7)}$. The preferred methods for surgical treatment are percutaneous vertebroplasty and kyphoplasty ${ }^{(6)}$, but balloon kyphoplasty applications increased in recent years because they provide better VCH (97\% vs 30\%) and are safer due to the decreased risk of cement leakage owing to the cavity it creates ${ }^{(6,7)}$.

Traditionally, successful results have been reported in the bipedicular kyphoplasty procedure ${ }^{(1,7)}$. In the current literature, studies have recommended the unipedicular approach due to its advantages, such as a shorter operative time, low cement leakage, low radiation exposure and low $\operatorname{cost}^{(7,8)}$.

In this study, we reported the clinical and radiologic efficacy of percutaneous unipedicular kyphoplasty in thoracolumbar OVCF in elderly patients. 


\section{MATERIALS AND METHODS}

\section{Study Design and Participants}

Our study was conducted as a retrospective analysis. Between January 2015 and December 2018, patients who underwent percutaneous unipedicular kyphoplasty in a tertiary hospital due to thoracolumbar OVCF at the T11-L2 levels (Table 1) $(\text { Singh index }<3)^{(9)}$ were enrolled. Patients with pathologic fractures (metastasis, cancer), neurologic disease, history of infection, multiple levels of kyphoplasty and multiple trauma were excluded. Our study protocol was approved by the local ethics committee (no: 56-859/05.2020).

\section{Surgical Method}

After the fracture, the patients were followed up with conservative treatment, and surgical decision was made for patients with unsuccessful results. The time between the occurrence of fracture and day of hospitalisation was $<8$ weeks. Surgery was performed within $48 \mathrm{~h}$ after hospitalisation for all patients who decided to undergo surgery. The patients were prepared by lying in the prone position under local anaesthesia and sedation. The surgical procedure was performed percutaneously and unipedicular with the same kyphoplasty system by the same surgeon, approaching the fractured vertebral segment from the left side. After the level was determined using C-arm fluoroscopy, the kyphoplasty cannula was placed in the pedicle. Two-planed (anteroposterior and lateral) images were checked to ensure proper placement of the cannula. The cavity created by inflating the balloon sent from the cannula was filled with polymethylmethacrylate cement. The patients were assessed neurologically and radiologically, and then the

Table 1. Clinical and demographic features

\begin{tabular}{ll}
\hline Variables & Results \\
\hline Age (years) & $76.64 \pm 5.5$ \\
\hline Gender & $28(26.4)$ \\
\hline Male & $49(63.6)$ \\
\hline Female & \\
\hline Fracture region & $40(51.9)$ \\
\hline Thoracic & $37(48.1)$ \\
\hline Lumbar & \\
\hline Level of fracture & $7(9.1)$ \\
\hline Thoracic 11 & $33(42.8)$ \\
\hline Thoracic 12 & $26(33.8)$ \\
\hline Lumbar 1 & $11(14.3)$ \\
\hline Lumbar 2 & \\
\hline Singh index & $23(29.8)$ \\
\hline 1 & $34(44.1)$ \\
\hline 2 & $20(25.9)$ \\
\hline 3 & \\
\hline n: Number & \\
Data are presented as mean \pm standard deviation or $\mathrm{n}(\%)$ \\
\hline
\end{tabular}

surgery was terminated. The patients were mobilised after $2 \mathrm{~h}$ on the same day and discharged after $6 \mathrm{~h}$.

\section{Data Collection and Assessment Tools}

Data were obtained from the patients' records. Clinical and demographic characteristics were recorded. Two-planed graphs (anteroposterior and lateral) and computed tomography scans of all patients were examined. The local kyphosis angle (LKA) of the fractured vertebrae was measured between the upper and lower end-plates, and the VCH was measured along with the heights of the lower and upper intact adjacent vertebrae ${ }^{(10)}$. Measurements were performed independently by two experienced surgeons, and their mean values were obtained. The Visual Analogue scale (VAS) ${ }^{(11)}$ and Oswestry disability index (ODI) were used for the primary functional outcomes of the patients. The ODI has been validated for the Turkish population ${ }^{(12)}$.

\section{Statistical Analysis}

Statistical analyses were performed using the Statistical Package for the Social Sciences software (SPSS Inc., Chicago, IL, USA). The conformity of the data to normal distribution was assessed using the Kolmogorov-Smirnov test. Descriptive data were reported as mean \pm standard deviation or median (interquartile range) values. Categorical variables were compared using the chi-square test or Fischer exact test. Student t-test or MannWhitney $\mathrm{U}$ test was used for comparisons between the groups. Risk factors were determined by using the binary logistic regression analysis. Statistical significance was determined at $\mathrm{p}<0.05$.

\section{RESULTS}

This study included 77 patients (28 men, 49 women) with a mean of age $76.64 \pm 5.5$ years (range, 69-86 years) were included. The clinical and demographic properties of the patients are summarised in Table 1. All patients showed improved values 24 months postoperatively compared with preoperative values, with decreased VAS scores, ODI scores, improved LKA and increased VCH ( $p<0.05$ for all) (Table 2) (Figure 1). None of the patients had any neurologic or systemic complications. One patient who underwent L2 vertebral kyphoplasty developed spinal block under the L2 spinal level during the procedure. No cement leakage was observed outside the corpus under C-arm fluoroscopy. It was concluded that the block was caused by local anaesthetic escaping into the spinal canal. The block completely resolved after $4 \mathrm{~h}$. As local complications, cement leakage from the kyphoplasty cannula tract to the posterior of the corpus was found in six patients, and cement leakage to the anterior was found in four patients. However, these conditions caused no pathology or symptoms.

\section{DISCUSSION}

The main objective of this study was to evaluate the effectiveness of unipedicular kyphoplasty in thoracolumbar 
turkishspine

OVCF in older patients by comparing pre- and postoperative radiologic and clinical values. Radiologically, LKA values were significantly decreased, and VCH values increased. ODI values along with VAS were clinically significantly decreased. Kyphoplasty can be performed with a single balloon and a single pedicle with local anaesthesia, thereby avoiding general anaesthesia complications, making it a reliable and effective, cheap method.

According to the literature, the traditional method used in percutaneous surgery of OVCF is bipedicular kyphoplasty, and good results have been reported ${ }^{(1,7)}$. However, some studies also advocate the unipedicular approach ${ }^{(7,8)}$. In their prospective study, Rebolledo et al.(13) compared both techniques and noted that radiologic and clinical outcomes were similar, but the unipedicular technique significantly reduced surgical time. In another meta-analysis, including six randomised controlled trials, Xiang et al. ${ }^{(14)}$ reported that the unipedicular technique was advantageous in terms of cost, operative time and radiation exposure, although the clinical results were the same. The cost is low in unipedicular kyphoplasty where a single balloon is used. General anaesthesia is associated with increased morbidity risk

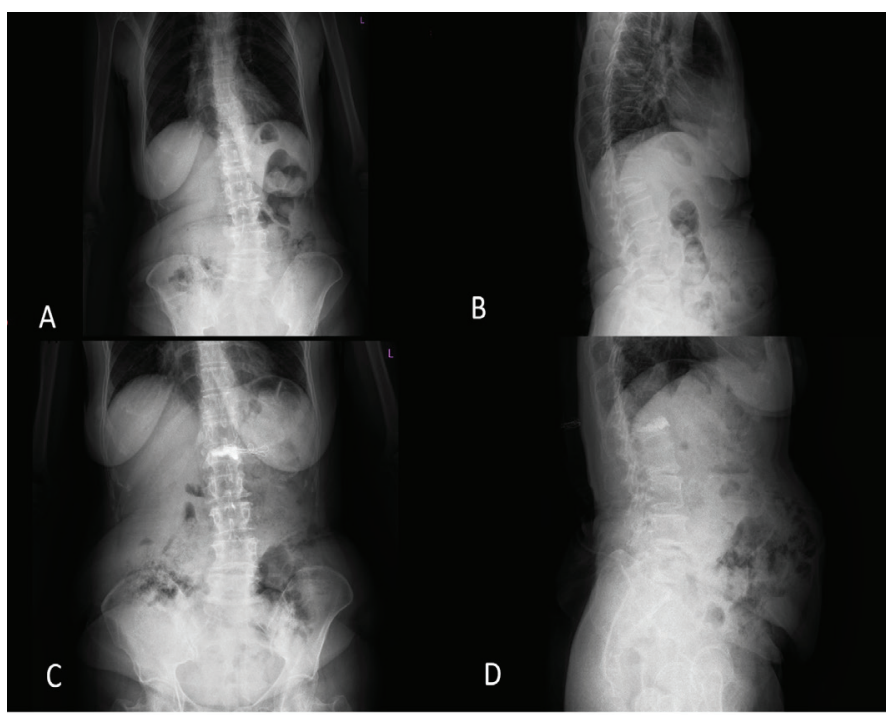

Figure 1. Radiographic images of a 74-year-old female patient Preoperative anterior-posterior (A) and lateral (B) images show the compression fracture of the L1 vertebra. Postoperative anterior-posterior (C) and lateral (D) images illustrate the improvement in local kyphosis and vertebral height after kyphoplasty in elderly patients, such as hypothermia, respiratory depression, atelectasis, pneumonia and myocardial infarction ${ }^{(15,16)}$. In terms of complications, the administration of local anaesthesia is advantageous; however, to avoid the development of nerve root anaesthesia, the needle should not enter too deeply into the junction of the pedicle and vertebral body ${ }^{(16)}$. Regarding the neurologic deficits that may occur, early detection through the ability to communicate with patients is another advantage. Therefore, the administration of local anaesthesia or sedationassisted local anaesthesia is one of the preferred methods. Liu et al. ${ }^{(16)}$ reported that extrapedicular infiltration of anaesthesia for unipedicular kyphoplasty was superior for patients' comfort. We performed the procedures in our clinic under local anaesthesia. Although patients perceive some pain during balloon inflation, this was only temporary, and they remained comfortable.

Cement leakage and adjacent vertebral fractures are common complications ${ }^{(17)}$. The cement leakage rate in percutaneous applications was $18.4 \%^{(18)}$, and the fracture rate in adjacent vertebrae was between $7.9 \%$ and $24 \%{ }^{(19)}$. The most important risk factor for these complications was the large amount of cement used ${ }^{(18,20)}$. In the literature, the incidence of neurologic deficits due to cement leakage into the epidural space was $0.03 \%$, and the incidence of pulmonary embolism due to cement leakage into the venous circulation was $0.01 \%^{(21)}$. Belkoff(22) reported that $2 \mathrm{cL}$ cement volume was sufficient. However, re-fracture may occur in the zone without cement leakage as complication if the cement cannot be placed in the middle of the vertebral corpus ${ }^{(23)}$. In the literature, successful results have also been reported with unipedicular kyphoplasty in procedures other than OVCF. Papanastassiou et al.(24) compared bi- and unipedicular kyphoplasty in a patient with multiple myeloma and reported that no difference was observed between clinical and radiologic results. We have used this method in selected diseases other than OVCF and achieved successful results.

\section{Study Limitations}

The main limitation of our study is its retrospective design, as well as the small number of patients and lack of a control group.

\section{CONCLUSION}

In view of our study results, percutaneous unipedicular kyphoplasty surgery in thoracolumbar OVCF in elderly patients is a reliable method if the indication is correct. With this

Table 2. Radiologic and clinical comparison after surgery

\begin{tabular}{llll}
\hline Variables & Preoperative & $\begin{array}{l}\text { Postoperative } \\
(24 \text { months) }\end{array}$ & p value \\
\hline LKA $\left({ }^{\circ}\right)$ & $17.56 \pm 4.1$ & $12.81 \pm 2.7$ & $<0.05$ \\
\hline VCH $(\mathrm{mm})$ & $16.45 \pm 2.3$ & $25.50 \pm 2.7$ & $<0.05$ \\
\hline ODI score & $14.78 \pm 2.2$ & $6.42 \pm 1.3$ & $<0.05$ \\
\hline VAS score & $6.25 \pm 1.8$ & $1.70 \pm 1.1$ & $<0.05$ \\
\hline LKA: Local kyphosis angle, $V$ CH: Vertebral corpus height, ODI: Oswestry Disability index, VAS: Visual Analogue scale &
\end{tabular}


method, significant reduction in pain and satisfactory clinical and radiological results can be obtained.

\section{Ethics}

Ethics Committee Approval: This study was approved by the local ethics committee (no: 56-859/05.2020).

Informed Consent: This study was conducted as a retrospective analysis.

Peer-review: Internally peer-reviewed.

\section{Authorship Contributions}

Surgical and Medical Practices: E.K., Concept: E.K., F.S., Design: E.K., F.S., Data Collection or Processing: E.K., F.S., Analysis or Interpretation: E.K., F.S., Literature Search: E.K., F.S., Writing: E.K., F.S.

Conflict of Interest: No conflict of interest was declared by the authors.

Financial Disclosure: The authors declared that this study received no financial support.

\section{REFERENCES}

1. Cui Zhiyong, Tian Yun, Feng Hui, Yang Zhongwei. Unilateral versus bilateral balloon kyphoplasty for osteoporotic vertebral compression fractures: a systematic review of overlapping meta-analyses. Pain physician. 2019;22:15-28.

2. Chen H, Tang P, Zhao Y, Gao Y, Wang Y. Unilateral versus bilateral balloon kyphoplasty in the treatment of osteoporotic vertebral compression fractures. Orthopedics. 2014;37:e828-35.

3. Jung HJ, Park YS, Seo HY, Lee JC, An KC, Kim JH, et al. Quality of life in patients with osteoporotic vertebral compression fractures. J Bone Metab. 2017;24:187-96.

4. Sun H, Lu PP, Liu YJ, Yang X, Zhou PH, Shen XF, et al. Can unilateral kyphoplasty replace bilateral kyphoplasty in treatment of osteoporotic vertebral compression fractures? A systematic review and metaanalysis. Pain physician. 2016;19:551-63.

5. Rostom S, Allali F, Bennani L, Abouqal R, Hajjaj-Hassouni N. The prevalence of vertebral fractures and health-related quality of life in postmenopausal women. Rheumatol Int. 2012;32:971-80.

6. Goz V, Koehler SM, Egorova NN, Moskowitz AJ, Guillerme SA, Hecht AC, et al. Kyphoplasty and vertebroplasty: trends in use in ambulatory and inpatient settings. Spine J. 2011;11:737-44.

7. Feng $H$, Huang $P$, Zhang $X$, Zheng G, Wang Y. Unilateral versus bilateral percutaneous kyphoplasty for osteoporotic vertebral compression fractures: A systematic review and meta-analysis of RCTs. J Orthop Res. 2015;33:1713-23.

8. Jun L, Zhang L, Yang HL. "Unilateral versus bilateral balloon kyphoplasty for osteoporotic vertebral compression fractures." Pain Physician. 2013;16:447-53.

9. Soontrapa S, Srinakarin J, Chowchuen P. Singh index screening for femoral neck osteoporosis. J Med Assoc Thai. 2005;88:S13-6.
10. Radcliff K, Su BW, Kepler CK, Rubin T, Shimer AL, Rihn JA, et al. Correlation of posterior ligamentous complex injury and neurological injury to loss of vertebral body height, kyphosis, and canal compromise. Spine. 2012;37:1142-50.

11. Price DD, McGrath PA, Rafii A, Buckingham B. The validation of visual analogue scales as ratio scale measures for chronic and experimental pain. Pain. 1983; 17:45-56.

12. Yakut $E$, Düger $T$, Öksüz Ç, Yörükan $S$, Üreten $K$, Turan $D$, et al. "Validation of the Turkish version of the Oswestry Disability Index for patients with low back pain." Spine. 2004;29:581-5.

13. Rebolledo BJ, Gladnick BP, Unnanuntana A, Nguyen JT, Kepler CK, Lane JM. Comparison of unipedicular and bipedicular balloon kyphoplasty for the treatment of osteoporotic vertebral compression fractures: a prospective randomised study. The Bone Joint J. 2013;95:401-6.

14. Xiang GH, Tong MJ, Lou C, Zhu SP, Guo WP, Ke CR. The role of unilateral balloon kyphoplasty for the treatment of patients with OVCFS: a systematic review and meta-analysis. Pain physician. 2018;21:209-18.

15. Kanonidou Z, Karystianou G. Anesthesia for the elderly. Hippokratia. 2007;11:175-7.

16. Liu L, Cheng S, Lu R, Zhou Q. Extrapedicular infiltration anesthesia as an improved method of local anesthesia for unipedicular percutaneous vertebroplasty or percutaneous kyphoplasty. BioMed research international, 2016. doi: 10.1155/2016/5086414 [Epub 2016 Sep 28].

17. Tiryaki M, Gül A, Gergin YE, Kendirlioğlu BC, Tatarlı N. KYPHOPLASTY: EVALUATION OF 108 PATIENTS. JTSS. 2016;27:97-100.

18. Lin D, Hao J, Li L, Wang L, Zhang H, Zou W, et al. Effect of bone cement volume fraction on adjacent vertebral fractures after unilateral percutaneous kyphoplasty. Clin Spine Surg. 2017;30:E270-5.

19. Suwal SK, Gang L, Kui H. Review on percutaneous vertebroplasty vs khyphoplasty for osteoporotic vertebral compression fracture. IJSIT. 2016;5:64-74.

20. Yüvrük E, Çalişaneller T, Önen MR, Naderi S. Effectiveness of vertebroplasty and kyphoplasty in osteoporotic vertebral body compression fractures: a comperative study. I Turk Spinal Surg. 2015;26:11-5.

21. Boonen S, Wahl DA, Nauroy L, Brandi ML, Bouxsein ML, Goldhahn J, et al. Balloon kyphoplasty and vertebroplasty in the management of vertebral compression fractures. Osteoporosis International. 2011;22:2915-34.

22. Belkoff SM. Biomechanics of vertebroplasty. In Advances in Spinal Fusion. CRC Press. 2003;pp:33-42

23. Frankl J, Hennemeyer C. Vertebral refracture after unipedicular kyphoplasty resulting in lateralized cement distribution. J Vasc Interv Radiol. 2015;12:1906-8.

24. Papanastassiou ID, Eleraky M, Murtagh R, Kokkalis ZT, Gerochristou $M$, Vrionis FD. Comparison of unilateral versus bilateral kyphoplasty in multiple myeloma patients and the importance of preoperative planning. Asian Spine J. 2014;8:244. 